\title{
Effects of Cyclic Freezing and Thawing on the Shear Behaviors of an Expansive Soil under a Wide Range of Stress Levels
}

Wei-lie Zou

Wuhan University

Zhong Han ( $\square$ zhong.han@whu.edu.cn )

Wuhan University https://orcid.org/0000-0002-8801-6503

Gui-tao Zhao

Wuhan University

Kewei Fan

Wuhan University

Sai K. Vanapalli

University of Ottawa

Xiequn Wang

Wuhan University of Technology

\section{Research Article}

Keywords: Expansive soil, Freeze-thaw, Microstructure, Volumetric change, Shear behavior

Posted Date: June 3rd, 2021

DOI: https://doi.org/10.21203/rs.3.rs-507911/v1

License: (c) (1) This work is licensed under a Creative Commons Attribution 4.0 International License.

Read Full License

Version of Record: A version of this preprint was published at Environmental Earth Sciences on January 25th, 2022. See the published version at https://doi.org/10.1007/s12665-022-10190-6. 
Effects of cyclic freezing and thawing on the shear behaviors of an

\section{expansive soil under a wide range of stress levels}

Wei-lie Zou ${ }^{1,2,3}$, Zhong Han ${ }^{2,3 *}$, Gui-tao Zhao ${ }^{2, *}$, Ke-wei Fan ${ }^{2}$, Sai K. Vanapalli ${ }^{4}$, Xie-qun Wang ${ }^{5}$

7

8

A manuscript submitted to Environmental Earth Sciences

for possible review and publication 


\section{ABSTRACT}

The focus of this paper is directed towards investigating the influence of multiple freeze-thaw (FT) cycles on the stress-strain relationships during undrained shearing for an expansive soil under a wide range of confining stresses $\left(\sigma_{\mathrm{c}}\right)$ from 0 to $300 \mathrm{kPa}$. Different numbers of FT cycles were applied to compacted specimens. The influence of FT cycles on the soil's structure was investigated using mercury intrusion porosimetry (MIP) and scanning electron microscope (SEM) tests. FT impacted specimens were subjected to consolidated undrained (CU) shear tests with pore pressure measurement $\left(\sigma_{\mathrm{c}}=10\right.$ to $\left.300 \mathrm{kPa}\right)$ and unconfined compression (UC) tests $\left(\sigma_{\mathrm{c}}=0 \mathrm{kPa}\right)$ to derive the shearing stress-strain relationships and the associated mechanical properties including (i) failure strength $\left(q_{\mathrm{u}}\right)$, elastic modulus $\left(E_{\mathrm{u}}\right)$, effective and apparent cohesion ( $c^{\prime}$ and $\left.c\right)$, and effective and apparent friction angle $\left(\phi^{\prime}\right.$ and $\left.\phi\right)$ obtained from CU tests and (ii) $q_{\mathrm{u}}$ and reloading modulus $\left(E_{1 \%}\right)$ and stress $\left(S_{\mathrm{u} 1 \%}\right)$ at $1 \%$ strain obtained from UC tests. Testing results show that FT cycles mainly influence the soil's macropores with diameters between 5 and 250 microns. Cracks develop during FT cycles and result in slight swelling which contributes to an increase in the global volume of the soil specimens. There is a significant reduction in the investigated mechanical properties after FT cycles. They typically achieve equilibrium after about 6 cycles. The shearing stress-strain curves transits from strain-softening to strain-hardening as the confining stress increases. An empirical model is developed to describe the strain-softening behavior of the specimens under low confining stresses. The model is simple to use and well describes all stress-strain curves obtained in this study that show strain-softening characteristics.

Keywords: Expansive soil; Freeze-thaw; Microstructure; Volumetric change; Shear behavior. 


\section{Highlights:}

49 - FT cycles destruct macropores and contribute to micro- and macrocracks

50 - The strength degradation associated with microstructural changes is explained

51 - The strain-softening behaviors under low stress levels of FT cycles are modeled 
53 Expansive soils are typically referred to as problematic soils by geotechnical engineers because of their significant swelling and shrinkage characteristics associated with variations in their water content ( $\mathrm{Li}$ et al. 1992; Nelson and Miller 1992; Zou et al. 2018). These soils are widely distributed in many countries in the world, which include India, Israel, Canada, Australia, China, and the USA (Jones and Holtz 1973; Ramana, 1993). The complex variations in their engineering properties have a significant influence that results in damages to the geotechnical infrastructures constructed on or adjacent to them. Expansive soils typically lead to non-uniform settlement of structures, cracking of walls and pavements, and landslides of expansive soil slope (Holtz and Gibbs 1956; Aitchison et al. 1973; Alonso et al. 1987; Chen, 1988; Schick et al. 1999; Miao et al. 2002; Tripathy et al. 2002; Glade, 2005; Ajdari et al. 2013; Zhang et al. 2015; Massat et al. 2016; Zou et al. 2020). According to a recent study by Adem and Vanapalli (2013), the economic losses caused by expansive soils were estimated to be approximately several billion dollars in many countries in recent years.

There is a rapid development of geotechnical infrastructure in expansive soils regions in China that are typically subjected to numerous freeze-thaw cycles annually (Lai et al. 2012; Kong et al. 2018; Tang et al. 2018). A new large-scale water conveyance canal constructed in Northeast China, which is $203 \mathrm{~km}$ in length, is an example of such an infrastructure in typical weak and medium expansive soils (Xu et al. 2016). The expansive soils in this region are subjected to periodic freeze-thaw (FT) cycles with fluctuations in the ground temperature. Due to this reason, there is ice formation and the migration of water in the expansive soils engineering properties, which include, coefficient of permeability, shear strength and 
2017). There is evidence to show that these changes have contributed to numerous landslides in the water conveyance canal (Xu et al. 2016; Zhang et al. 2018).

Expansive soils contain high quantities of swelling clay minerals such as montmorillonite and illite that have a significant influence on the volumetric variations during cyclical moisture content changes (Alonso et al. 1999; Tripathy et al. 2002). The volume change is typically characterized by significant expansion and weakening upon wetting and shrinkage and cracking upon drying, which cause extensive damages to the adjacent infrastructure and even result in natural disasters (Holtz and Gibbs 1956; Berndt and Coughlan 1976; Chen and Ma 1987; Chen 1988; Lin and Cerato 2013; Gatabin et al. 2016; Liu et al. 2020). A significant number of studies focused on the effect of drying-wetting cycles on the structural, volumetric, and hydro-mechanical behaviors of expansive soils (Grant 1974; Albrecht and Benson 2001; Cui et al. 2002; Alonso et al. 2005; Cuisinier and Masrouri 2005; Pires et al. 2008; Nowamooz and Masrouri 2008; Ajdari et al. 2013; Wang et al. 2017). Also, several studies have investigated the influence of freeze-thaw cycles on the mechanical behavior of various soils, such as saline soil (Han et al. 2018), loess (Li et al. 2018), dispersive soil (Han et al. 2021), silty soil (Cui et al. 2014; Chen et al. 2019) and mine tailings (Liu et al. 2018). However, due to the expansive soils' complex deformation characteristics, the evolution of engineering properties of expansive soils during FT cycles are more complex in comparison to conventional soils. There are limited studies in the literature that address the effects of FT cycles on the microstructure and mechanical behavior of expansive soils. In particular, the effects of FT cycles on mechanical behaviors under low stress levels are not well understood.

In this study, the volumetric characteristics, the stress versus strain relationships, and shear strength behaviors of an expansive soil collected from Northeastern China under the effects 
of FT cycles were investigated. The investigated mechanical behaviors include (i) unconfined compression strength and the unloading-reloading modulus, (ii) shear strength, elastic modulus, and strength parameters (i.e. cohesion and internal friction angle) that were obtained from consolidated undrained shear tests. Microstructural changes were derived from mercury intrusion porosimetry (MIP) and scanning electron microscope (SEM) tests. Besides, an empirical model is proposed to describe the strain-softening behavior of expansive soil specimens under low confining pressures that can serve as a useful numerical tool.

\section{EXPERIMENTAL INVESTIGATIONS}

\subsection{Materials}

An expansive soil collected from Qiqihar, Heilongjiang, China is used for this research study. The sampling site is a typical seasonally frozen region characterized by hot summer and cold winter. The average temperature ranges from $23.1^{\circ} \mathrm{C}$ in summer to $-18.6^{\circ} \mathrm{C}$ in winter. The expansive soil was excavated from approximately $1 \mathrm{~m}$ beneath the ground surface, and the in-situ natural gravimetric water content $\left(w_{n}\right)$ and dry density $\left(\rho_{d n}\right)$ of the sampled soil was $26.3 \%$ and $15.09 \mathrm{kN} / \mathrm{m}^{3}$, respectively. Physical index properties of the tested soil are summarized in Table 1.

XRF tests were conducted to determine the chemical components of the soil. The major chemical components and their contents by mass are $\mathrm{SiO}_{2}, 60.48 \% ; \mathrm{Al}_{2} \mathrm{O}_{3}, 18.53 \% ; \mathrm{Fe}_{2} \mathrm{O}_{3}$, $6.63 \% ; \mathrm{K}_{2} \mathrm{O}, 3.05 \%$; $\mathrm{CaO}, 4 \%$. XRD tests were conducted to reveal the mineral components of the soil. The major minerals are Quartz, Illite, Albite, and Calcite. According to the standard of GB 50112-2013 (Ministry of Housing and Urban-Rural Development, P.R. China, 2013) and the free swelling ratio of $67 \%$, this soil is classified as moderately expansive soil. 


\subsection{Specimen preparation and application of FT cycles}

The collected expansive soil samples were air-dried, pulverized with a rubber mallet, and then passed through a $2 \mathrm{~mm}$ sieve to remove gravels and large size particles. To simulate the field condition, the air-dried soil was wetted with water such that the natural water content of $26.3 \%$ is achieved. The moist soil was statically compacted at the natural dry density of $1540 \mathrm{~kg} / \mathrm{m}^{3}$ into cylindrical specimens $(38 \mathrm{~mm}$ in diameter and $76 \mathrm{~mm}$ in height) for microstructure investigations and triaxial tests. Compacted specimens were sealed in layers of Saran wrap and stored in plastic containers for at least $72 \mathrm{~h}$ at room temperature of $25 \pm 1^{\circ} \mathrm{C}$ to ensure that water was evenly distributed within the specimens.

Specimens were subjected to freeze-thaw cycles in a closed-system condition. There is limited or no moisture migration during freezing and thawing processes because of the relatively low coefficient permeability of expansive soils, especially under unsaturated and frozen conditions (Chamberlain 1973; Yarbasi et al. 2007; Lu et al. 2018). A temperature chamber with a precision of $\pm 0.05^{\circ} \mathrm{C}$ and a temperature range from $100^{\circ} \mathrm{C}$ to $-40^{\circ} \mathrm{C}$ was used to apply FT cycles.

During FT cycles, all specimens remain wrapped in Saran sheets and stored in plastic containers which were firstly frozen at $-20^{\circ} \mathrm{C}$ for at least $12 \mathrm{~h}$ and then allowed to thaw at $20^{\circ} \mathrm{C}$ for another $12 \mathrm{~h}$. The temperature range was chosen following the local annual temperature variation (i.e. $-18.6^{\circ} \mathrm{C}$ to $23.1^{\circ} \mathrm{C}$ ). A $12 \mathrm{~h}$ period is considered enough for achieving equilibrium conditions as small-size specimens are used in this study (Lu et al. 2019; Ding et al. 2020). Such freezing and thawing procedure was repeated until the 
designated number of FT cycles (i.e. $\left.N_{\mathrm{FT}}=0,1,4,6,10\right)$ was reached.

151

152

153

154

155

156

157

\subsection{Measurement of volumetric change}

To study the volumetric behavior of expansive soil specimens during FT cycles, the volume measurements were performed on specimens after each freezing and thawing process. An electronic Vernier caliper with an accuracy of $0.005 \mathrm{~mm}$ was used to directly measure the diameter and height of the specimens. Preliminary studies have shown that the volumetric strain $\left(\varepsilon_{\mathrm{v}}\right)$ during FT cycles was found to be uniform in the homogenous soil specimens which is consistent with the assumption of the uniform distribution of water phase in soil mass and is widely used by various researchers (Zeng et al. 2018; Lu et al. 2019). Thus, diameter (i.e. $d_{1}, d_{2}$, and $d_{3}$ ) and height (i.e. $h_{1}, h_{2}$, and $h_{3}$ ) measurements were taken at three different cross-sections that are evenly distributed on the surface of the specimens. The average values of diameter and height measurements were used to calculate the global volume of the specimens and the void ratio $(e)$ or volumetric strain $\left(\varepsilon_{\mathrm{v}}\right)$ - water content $(w)$ relationships.

\subsection{MIP and SEM tests}

To track the evolution of the microstructure of specimens upon freeze-thaw cycles, the mercury intrusion porosimetry (MIP) tests and scanning electron microscopy (SEM) tests were performed on untreated specimens and specimens subjected to $1,4,6$, and 10 FT cycles. MIP tests determine quantitatively the distribution and size of soil's pores while SEM tests capture the cross-section morphology of the microstructure. 
173 Approximately $2 \mathrm{~g}$ of mass trimmed from test specimens subjected to different FT cycles were collected for use in MIP and SEM tests. They were freeze-dried in liquid nitrogen to preserve the soil structure and remove the pore water before testing. The trimmed specimens were then subjected to MIP tests in a PoreMaster 33 porosimeter and SEM tests in an FEI Quanta 200 SEM testing system.

\subsection{Determination of mechanical properties}

A GDS static triaxial testing system (manufactured by GDS Instruments Ltd., Hampshire, U.K., as shown in Figure 1), was utilized for the consolidated undrained (CU) triaxial compression tests and unconfined compression (UC) tests to determine the mechanical properties of expansive soil subjected to FT cycles. It should be noted that the UC tests were performed on both saturated (specimens after achieving designed FT cycles were saturated before performing the tests) and unsaturated specimens (specimens after achieving designed FT cycles were directly used for tests), while CU tests were only performed on saturated specimens.

Before performing the CU triaxial compression tests, the untreated specimens were subjected to planned FT cycles and were vacuum saturated over a period of $24 \mathrm{~h}$. They were thereafter transferred to the triaxial chamber where they were further subjected to back-pressure saturated until the pore-water pressure parameter, $B$ exceeds 0.90 (Kamruzzaman et al. 2009). Afterward, the specimens were consolidated under seven different confining pressures $\left(\sigma_{\mathrm{c}}\right)$ of $10,20,30,50,100,200,300 \mathrm{kPa}$. The consolidation process was assumed to have been completed when the specimens' volumetric changes leveled off and their excess pore water 
pressure has dissipated. Finally, the specimens were sheared under undrained conditions at a shear strain rate of $0.066 \% / \mathrm{min}$ until the axial strain reached $20 \%$.

The unconfined compression (UC) tests following the methodology suggested by Han and Vanapalli (2017). This methodology involves an unloading-reloading loop starting at $1 \%$ axial strain $\left(\varepsilon_{\mathrm{a}}\right)$ to determine the axial stress at $\varepsilon_{\mathrm{a}}=1 \%$ before the unloading process (i.e. $\left.S_{\mathrm{u} 1 \%}\right)$ and the reloading modulus at $\varepsilon_{\mathrm{a}}=1 \%$ (i.e. $\left.E_{1 \%}\right)$. The unconfined compression strength $\left(q_{\mathrm{u}}\right)$ was determined after the specimens were loaded to failure. A loading and unloading rate of $1 \mathrm{~mm} / \mathrm{min}$ was adopted following the ASTM D2166-13 (2013) protocol. The $S_{\mathrm{u} 1 \%}$ and $E_{1 \%}$ are elastic properties and $q_{\mathrm{u}}$ indicates the unconfined shear strength of the specimens (Lee et al. 1997; Lu and Kaya 2013). Detailed discussions of the use of $E_{1 \%}, S_{\mathrm{u} 1 \%}$, and $q_{\mathrm{u}}$ and testing procedures of the revised UC tests are available in Lee et al. (1997) and Han and Vanapalli (2017). Figure 2 shows the schematic diagram of the stress-strain relationship during the revised UC tests and the determination of the $E_{1 \%}, S_{\mathrm{u} 1 \%}$, and $q_{\mathrm{u}}$.

\section{TESTS RESULTS AND DISCUSSIONS}

\subsection{Volumetric characteristics}

The volumetric strain $\left(\varepsilon_{\mathrm{v}}\right)$ of specimens during FT cycles can be defined using Eq. 1.

$$
\varepsilon_{v}=\left(V_{N}-V_{0}\right) / V_{0} \times 100 \%
$$

where $V_{0}$ is the initial volume of the untreated specimen, $V_{N}$ is the volume of the specimen after experiencing $N$ FT cycles. Positive $\varepsilon_{\mathrm{v}}$ indicates swelling while negative $\varepsilon_{\mathrm{v}}$ refers to shrinkage. 
219 The evolution of $\varepsilon_{\mathrm{v}}$ during 1, 4, 6, 10 FT cycles is shown in Figure 3. The volume change of specimens with different $N_{\mathrm{FT}}$ shows similar features (i) there is an increase in the $\varepsilon_{\mathrm{v}}$ (i.e. expansion) during the freezing process and (ii) there is a decrease in the $\varepsilon_{\mathrm{v}}$ (i.e. shrinkage) during the thawing process. The $\varepsilon_{\mathrm{v}}$ during initial several FT cycles are significant but its scale reduces gradually with an increase in the $N_{\text {FT. }}$ The volumetric deformation behavior is elastic after about 4 FT cycles, meaning that the non-recoverable $\varepsilon_{\mathrm{v}}$ becomes almost negligible when $N_{\text {FT }} \geq 4$, which is consistent with the observations of other similar studies reported in the literature (Viklander 1998; Wang et al., 2017; Zeng et al., 2018). FT cycles result in a slight expansion of $\varepsilon_{\mathrm{v}}\left(\varepsilon_{\mathrm{v}}=1.2 \%\right)$ in the specimens' volume after $10 \mathrm{FT}$ cycles.

\subsection{Evolution of soils' microstructure}

The MIP test results of specimens subjected to different FT cycles $\left(N_{\mathrm{FT}}=0,1,4,6,10\right)$ are plotted in Figure 4. Related SEM images are shown in Figure 5. MIP results are presented in CI curves (i.e. $-\delta e_{\mathrm{MIP}} / \delta \log d$ versus $\log d$ relationships). macro-pores at about $30 \mu \mathrm{m}$. This observation is consistent with the previous studies that the as-compacted specimens usually show bimodal PSD curves (Wang et al, 2014; Burton et al, 2015). Macropores with diameters close to $30 \mu \mathrm{m}$ also can be observed in SEM images (see 
245 For a better description of the microstructure's evolution during FT histories, the CI and PSD

246 curves were separated into three zones (i.e. zones A, B, and C) by two boundaries which are

247 defined at $0.1 \mu \mathrm{m}$ and $5 \mu \mathrm{m}$ (see Figure 4). $0.1 \mu \mathrm{m}$ is chosen because all PSD curves converge 248 at the left of this threshold suggesting that these pores with diameters smaller than $0.1 \mu \mathrm{m}$ are 249 hard to be affected during FT cycles. $5 \mu \mathrm{m}$ is chosen as the delimiting boundary separating the macro-pores and micro-pores in PSD curves of the tested soil, which is consistent with the criterion proposed by Burton et al. (2015). 5 $\mu \mathrm{m}$ is the turning point of PSD and CI curves which refer to the beginning of the main population of micro-pores.

In order to quantitatively evaluate the variation of microstructures, the void ratio in zones $\mathrm{A}$,

$\mathrm{B}$, and $\mathrm{C}$ (denoted as $\left.\Delta e_{\mathrm{MIP}, \mathrm{A}}, \Delta e_{\mathrm{MIP}, \mathrm{B}}, \Delta e_{\mathrm{MIP}, \mathrm{C}}\right)$ are calculated by $e_{\mathrm{MIP}, \mathrm{A}}=e_{\mathrm{MIP}, 0.01}-e_{\mathrm{MIP}, 0.1}$, $e_{\mathrm{MIP}, \mathrm{B}}=e_{\mathrm{MIP}, 0.1}-e_{\mathrm{MIP}, 5}, e_{\mathrm{MIP}, \mathrm{C}}=e_{\mathrm{MIP}, 5}$ where $e_{\mathrm{MIP}, \mathrm{N}}$ is the $e_{\mathrm{MIP}}$ value at $\mathrm{N} \mu \mathrm{m}$. The $e_{\mathrm{MIP}, 0.01}$ is the total void ratio intruded by mercury in the MIP tests $\left(e_{\mathrm{MIP}, 0.01}=\Delta e_{\mathrm{MIP}, \mathrm{A}}+\Delta e_{\mathrm{MIP}, \mathrm{B}}+\Delta e_{\mathrm{MIP}, \mathrm{C}}\right)$. The values of $\Delta e_{\mathrm{MIP}, \mathrm{A}}, \Delta e_{\mathrm{MIP}, \mathrm{B}}, \Delta e_{\mathrm{MIP}, \mathrm{C}}$ and $e_{\mathrm{MIP}, 0.01}$ are summarized in Table 2.

The following information can be derived from Figures 4 and 5 and Table 2:

(i) In Zone A, the FT cycles have a negligible effect on the microstructure as the shape of CI and PSD curves remain unchanged and the calculated void ratio in this zone (i.e. $\left.e_{\mathrm{MIP}, \mathrm{A}}\right)$ is approximately the same after different FT cycles.

(ii) In Zone $\mathrm{B}$, the $e_{\mathrm{MIP}, \mathrm{B}}$ decreases during FT cycles, such behavior suggests that some micro-pores transformed into macro-pores due to the ice crystal formation during the process of freezing. This is the result of irreversible frost-induced plastic deformation of soil particles in the subsequent thawing process. The peak of the micro-pores in the PSD curve shifts to the right, indicating a slight increase in the diameter of the 
dominant micro-pores. The frequency (i.e. $-\delta e_{\mathrm{MIP}} / \delta \log d$ ) corresponding to the peak of the PSD curve, also decreases after FT cycles.

(iii) In Zone $\mathrm{C}$, the $e_{\mathrm{MIP}, \mathrm{C}}$ increases during FT cycles, which confirms the transformation of micro-pores to macro-pores. The peak of compaction-induced macro-pores in the PSD curve of the initial untreated specimen disappears after a few FT cycles. However, a new plateau in the range of $5-20 \mu \mathrm{m}$ develops which is stable during FT cycles. This behavior also suggests that the compaction-induced macro-pores are unstable and prone to collapse upon FT processes.

(iv) The evolution of microstructures during FT cycles observed in MIP results is consistent with the SEM images. As shown in Figure 5, the variation of pores' size and the development of cracks induced by FT cycles can be easily observed. The cracks induced by FT cycles segregate the soil particles and ultimately lead to a fragmented soil structure.

\subsection{Unconfined compressive strength properties}

Figure 6 shows the stress-strain curves (i.e. axial stress, $\sigma_{1}$ versus axial strain, $\varepsilon_{1}$ ) obtained from unconfined compression tests on saturated and unsaturated specimens with different FT cycles $\left(N_{\mathrm{FT}}=0,1,4,6,10\right)$. The $\sigma_{1}-\varepsilon_{1}$ relationships show strain-softening characteristics. With an increase in the FT cycles, axial strain at the peak strength (denoted as $\varepsilon_{\mathrm{p}}$ ) increases from approximately $2 \%$ of the untreated specimen to $3 \%$ after 10 FT cycles, for both saturated and unsaturated specimens, and the pre-peak stress-strain curves tend to become flat. The stress-strain curves of specimens with different $N_{\text {FT }}$ seem to have an identical residual strength of approximately 15 and $30 \mathrm{kPa}$ for saturated and unsaturated specimens, respectively. Comparing Figure 6(a) and (b), it can be observed that the saturated specimens have lower residual strength and much lower peak strength than the unsaturated specimens, despite the 
consistent trends in stress-strain curves.

The evolution of $q_{\mathrm{u}}, E_{1 \%}$, and $S_{\mathrm{u} 1 \%}$ values with $N_{\mathrm{FT}}$ is shown in Figure 7. A power function (Eq. 1) is used to describe the variation of $q_{\mathrm{u}}, E_{1 \%}$, and $S_{\mathrm{u} 1 \%}$ with $N_{\mathrm{FT}}$ under unconfined compression.

$$
\frac{\Omega_{N}}{\Omega_{0}}=\frac{1+\alpha e^{-\beta N}}{1+\alpha}
$$

where $\Omega_{0}$ collectively represents the $q_{\mathrm{u}}, E_{1 \%}$, and $S_{\mathrm{u} 1 \%}$ of untreated specimens, $\Omega_{N}$ is the $q_{\mathrm{u}}$, $E_{1 \%}$, and $S_{\mathrm{u} 1 \%}$ after $\mathrm{N}$ cycles of treatment, $\alpha$ and $\beta$ are model parameters, $e=2.7182$. The fitting curves are shown in Figure 7 and the values of fitting parameters (i.e. $\alpha$, and $\beta$ ) are summarized in Table 3 . The variation in the $q_{\mathrm{u}}, E_{1 \%}$, and $S_{\mathrm{u} 1 \%}$ with $N_{\mathrm{FT}}$ is well described by the proposed power function with $R^{2}>0.9$. The following information can be derived from Figure 7 and Table 3:

(i) The $q_{\mathrm{u}}, E_{1 \%}$, and $S_{\mathrm{u} 1 \%}$ decrease with increasing $N_{\mathrm{FT}}$, especially during the initial two FT cycles $\left(N_{\mathrm{FT}}=1,4\right)$, which is followed by a slow decrease with further FT cycles and reach equilibrium for unsaturated tests of approximately $N_{\mathrm{FT}}=6$ and saturated tests of $N_{\mathrm{FT}}=4$, respectively.

(ii) The values of $q_{\mathrm{u}}, E_{1 \%}$, and $S_{\mathrm{u} 1 \%}$ obtained from saturated specimens are much lower than the ones of unsaturated specimens under the same $N_{\mathrm{FT}}$. For example, the $q_{\mathrm{u}}, E_{1 \%}$, and $S_{\mathrm{u} 1 \%}$ of saturated specimens decrease by $49.1 \%, 54.0 \%$, and $71.4 \%$ from the initial values of $55 \mathrm{kPa}, 8.45 \mathrm{MPa}$, and $49 \mathrm{kPa}$ for untreated specimens to $28 \mathrm{kPa}, 3.89 \mathrm{MPa}$, and $14 \mathrm{kPa}$ after 10 FT cycles, respectively. For unsaturated specimens, the $q_{\mathrm{u}}, E_{1 \%}$, and $S_{\mathrm{u} 1 \%}$ decrease only by $46.0 \%, 45.2 \%$, and $56.7 \%$ from $113 \mathrm{kPa}, 15.65 \mathrm{MPa}$ and $97 \mathrm{kPa}$ to $61 \mathrm{kPa}$, 8.57MPa, and $42 \mathrm{kPa}$, respectively. Thus, the decrease in the mechanical properties is more significant during FT cycles when the moisture content is higher. 


\subsection{Shear strength and elastic modulus during consolidated undrained shearing}

$319 \mathrm{CU}$ tests were conducted on specimens under seven confining stress levels $\left(\sigma_{\mathrm{c}}=10,20,30,50\right.$, $100,200,300 \mathrm{kPa})$ and with different $N_{F T}\left(N_{F T}=0,1,4,6,10\right)$ for comprehensive evaluation of the influence of FT cycles on the mechanical properties of expansive soil.

The stress-strain relationships (i.e. deviator stress $q$ versus axial strain $\varepsilon_{1} ; q=\sigma_{1}-\sigma_{\mathrm{c}}$ ) obtained from consolidated undrained triaxial shear tests under various confining pressures of the specimens subjected to FT cycles shown in Figure 8. The untreated specimens and the specimens subjected to FT cycles exhibit strain-softening behavior (see Figure 8) under low confining pressures (i.e. 10, 20, and $30 \mathrm{kPa}$ ). However, the strain-softening behavior gradually decreases with increasing confining pressure. The stress-strain curves start to show a strainstabilization behavior when the confining pressure exceeds $50 \mathrm{kPa}$ and show a strain-hardening behavior at a confining pressure of 100 and $300 \mathrm{kPa}$ (see Figure 8). The shear strength (i.e. $q_{\mathrm{u}}$ ) is equal to the peak deviator stress for the specimens exhibiting strain-softening characteristics. However, the shear strength is estimated at the axial strain of $15 \%$ for the specimens exhibiting strain stabilization or hardening characteristics (Zhang et al. 2015; Liu et al. 2018). Typical results of the failure strength due to FT cycles under low and high confining pressures are given in Figure 9. 20, and 30kPa). According to Wang et al. (2007) and Tang et al. (2018), a more compacted structure is formed due to the soil particle rearrangement associated with the closure of cracks induced due to the influence FT cycles. 
344 The elastic modulus (i.e. $E_{\mathrm{u}}$ ) is an important parameter that reflects the ability of a soil to resist deformation (Tang et al. 2018; Han et al. 2018). According to Lee et al. (1995), the elastic modulus can be calculated using Eq. (2) from stress-strain curves:

$$
E_{u}=\frac{\Delta q}{\Delta \varepsilon}=\frac{q_{1 \%}-q_{0}}{\varepsilon_{1 \%}-\varepsilon_{0}}
$$

where $\Delta q$ and $\Delta \varepsilon$ are the increments of deviator stress and axial strain, respectively; $q_{1 \%}$ is the deviator stress corresponding to an axial strain of $1 \%$ (i.e. $\varepsilon_{1} \%$ ), $q_{0}$ is the initial deviator stress corresponding to initial axial strain $\varepsilon_{0}$. The results of $E_{\mathrm{u}}$ for specimens subjected to FT cycles under various low and high confining pressures are given in Figure 10.

A significant reduction in the $E_{\mathrm{u}}$ with an increase in the $N_{\text {FT }}$ can be observed. Such behavior is due to the modified micro-structures introduced by freeze-thaw cycles, which greatly reduce the ability of specimens to resist elastic deformation. These observations are consistent with the variations of $q_{\mathrm{u}}$ that almost no appreciable decrease in the $E_{\mathrm{u}}$ was observed after $N_{\mathrm{FT}}=6$.

The effective and apparent cohesion $\left(c^{\prime}\right.$ and $\left.c, \mathrm{kPa}\right)$ and the effective and apparent cohesion internal fraction angle $\left(\phi^{\prime}\right.$ and $\left.\phi,^{\circ}\right)$ under each confining pressure was separately determined from the Mohr-Coulomb model (Eq. 3) to evaluate their evolutions with $N_{\text {FT }}$.

$$
\begin{gathered}
\sigma_{1}=\frac{2 c \cos \phi}{1-\sin \phi}+\frac{1+\sin \phi}{1-\sin \phi} \sigma_{3} \\
\sigma_{1}^{\prime}=\frac{2 c^{\prime} \cos \phi^{\prime}}{1-\sin \phi^{\prime}}+\frac{1+\sin \phi^{\prime}}{1-\sin \phi^{\prime}} \sigma_{3}^{\prime}
\end{gathered}
$$

The evolution of determined $c^{\prime}$ and $\phi^{\prime}$ and $c$ and $\phi$ with different $N_{\mathrm{FT}}$ are summarized in

Figures 11 and 12, respectively. 
367 Because of the particle rearrangement and compaction effects during the consolidation and shearing processes, the effective and apparent cohesion (i.e. $c^{\prime}$ and $c$ ) and internal friction angle (i.e. $\phi^{\prime}$ and $\phi$ ) exhibit a non-linear characteristic as the confining pressure increases. A lower cohesion and higher internal friction angle were observed for lower confining pressures, these results are consistent with the previous studies (Chen and Liu 1990; Jiang et al. 2003; and $\mathrm{Li}$ and Cheng 2012). An obvious reduction was also observed in the shear strength parameters $c^{\prime}$ and $\phi^{\prime}$ 'with the increasing cycle number, $N_{\mathrm{FT}}$. Such a behavior can be attributed to the influence of FT cycles that introduce cracks to soil structure (see Figure 5), which reduce the integrity of soil particles that results in a reduction of their effective contacts.

The aforementioned power function (Eq. 1) was also used to describe the variation of $q_{\mathrm{u}}, E_{\mathrm{u}}$, given in Table 4.

\section{MODELLING STRESS-STRAIN BEHAVIORS}

The strain stabilization and hardening behavior of specimens under high confining pressures (i.e. $\sigma_{\mathrm{c}}=50,100,200,300 \mathrm{kPa}$ ) can be described by the Duncan-Chang model (i.e. Eq. (4)) and shown in Figure 8.

$$
q=\frac{\varepsilon_{1}}{a+b \varepsilon_{1}}
$$

where $a$ and $b$ are model parameters. According to Gutierrez et al. (2008), Moniz (2009), and Ladd et al. (1977), 1/a is the slope of the initial curve and equals the undrained elastic modulus, $E_{\mathrm{u}} .1 / b$ is the ultimate deviator stress and indicates the undrained shear strength, $q_{\mathrm{u}}$. Fitting parameters and $R^{2}$ are summarised in Table 5. 
392 Extending the concepts of the Duncan-Chang model, an empirical model Eq. (5) was proposed to describe the strain-softening behavior of specimens subjected to different FT cycles which are observed from CU and UC tests.

$$
q=\frac{\varepsilon_{1}}{a+b \varepsilon_{1}} \lambda\left[\ln \left[2.718+\left(10^{10 \varepsilon_{1}} / \kappa\right)^{-n}\right]\right]^{m}
$$

396

where $\lambda, \kappa, n, m$, are model parameters. $\lambda$ is related to the ratio of residual strength to peak strength, $\kappa, n$, and $m$ are the model parameters related to the axial strain at peak deviator stress, the slope of descending portion of the stress-strain curves, and the axial strain at residual deviator stress.

The fitting curves are shown in Figures 6 and 8 and fitting parameters are summarised in Table 6 highlight good agreements between the measurements and the predictions. The residual axial strain and corresponding residual deviator stress and the subsequent horizontal section of stress-strain curves were well described.

\section{CONCLUSIONS}

In this paper, the influence of multiple FT cycles on the microstructure and mechanical behaviors (including volumetric behavior, stress-strain behavior, shear strength parameters, and elastic modulus during consolidated undrained shearing and shear strength and unloading-reloading modulus during unconfined shearing) of an expansive soil was investigated from experimental studies. The following observations and conclusions were derived.

(i) The compaction-induced macro-structures are altered in the range of 5 to 250 microns due to the influence of FT cycles. Besides, FT cycles introduce cracks into the soil structure. It is important to note that FT cycles have a minor influence on the 

approximately 4 cycles during FT treatments.

(ii) The $q_{\mathrm{u}}, E_{1 \%}$, and $S_{\mathrm{u} 1 \%}$ obtained from unconfined compression tests decrease significantly with increasing $N_{\mathrm{FT}}$, especially during the initial two FT cycles, and reach equilibrium after approximately 4 to 6 FT cycles. The values of $q_{\mathrm{u}}, E_{1 \%}$, and $S_{\mathrm{u} 1 \%}$ for saturated specimens are much smaller than the ones of unsaturated soil specimens for the same $N_{\text {FT }}$.

(iii) The $q_{\mathrm{u}}, E_{\mathrm{u}}, c$, and $\phi$ obtained from consolidated undrained triaxial tests reduce due to the influence of FT cycles; however, these are notably constant after 6 FT cycles.

A simple empirical model is developed to describe the strain-softening behavior of strain-softening behaviors that can be derived from the stress-strain curves.

\section{DECLARATIONS}

Acknowledgements

Authors gratefully acknowledge the funding received from the National Natural Science Foundation of China (Grant Nos. 51779191, and 51809199).

\section{Competent of Interests}

The authors declare that they have no known competing financial interests or personal relationships that could have appeared to influence the work reported in this paper.

\section{Authors' contributions}

Wei-lie Zou: Supervision, Methodology, Formal analysis, Validation, Writing-original draft.

Zhong Han: Supervision, Conceptualization, Funding acquisition, Project administration, Writing-review \& editing.

Gui-tao Zhao: Conceptualization, Methodology, Formal analysis, Writing-original draft.

Ke-wei Fan: Formal analysis, Writing-review \& editing.

Sai K. Vanapalli: Methodology, Writing-review \& editing.

Xie-qun Wang: Formal analysis, Writing-review \& editing.

\section{REFERENCES}

Adem, H.H., Vanapalli, S.K., 2013. Constitutive modeling approach for estimating 1-D heave with respect to time for expansive soils. Int. J. Geotech. Eng. 7 (2), 199-204.

Aitchison, G.D., Peter, P., Martin, R., 1973. The instability indices Ipm and Ips in expansive clays. In: Proc., 3rd International Conference on Expansive clays, 2. pp. 101-104 Haifa, Israel.

Ajdari M, Habibagahi G, and Masrouri F, (2013) The role of suction and degree of saturation on the hydro-mechanical response of a dual porosity silt-bentonite mixture. Appl Clay Sci 83-84, 83-90.

Albrecht, B. A., and Benson, C. H. 2001. Effect of desiccation on compacted natural clays. Journal of Geotechnical and Geoenvironmental Engineering, 127, 67-75. 
Aldaood, A., Bouasker, M., and Al-Mukhtar, M. 2014. Impact of freeze-thaw cycles on mechanical behavior of lime stabilized gypseous soils. Cold Regions Science and Technology, 99(1), 38-45.

Aldaood, A., Bouasker, M., Al-Mukhtar, M., 2016. Effect of water during freeze-thaw cycles on the performance and durability of lime-treated gypseous soil. Cold Reg. Sci. Technol. 123, 155-163.

Alonso, E.E., Gens, A., Hight, D.W., 1987. Special problems soils. In: Genera 1 Report., 9th European Conference on Soil Mechanics and Foundations Engineering, 3. pp. 1087-1146 Dublin, Ireland.

Alonso, E.E., Vaunat, J., Gens, A., 1999. Modelling the mechanical behaviour of expansive clays. Eng. Geol. 54 (1-2), 173183.

Alonso, E.E., Romero, E., Hoffmann, C., García-Escudero, E., 2005. Expansive bentoni- te-sand mixtures in cyclic controlled-suction drying and wetting. Eng. Geol. 81 (3), 213-226.

ASTM. Standard test method for unconfined compressive strength of cohesive soil. D2166-13, West Conshohocken, PA; 2013.

ASTM, 2017. Designation: D6913 / D6913M-17: Standard Test Methods for Particle-Size Distribution (Gradation) of Soils Using Sieve Analysis. American Society for Testing and Materials, West Conshohocken, PA.

ASTM, 2017. Designation: D7928-17: Standard Test Method for Particle-Size Distribution (Gradation) of Fine-Grained Soils Using the Sedimentation (Hydrometer) Analysis. American Society for Testing and Materials, West Conshohocken, PA.

ASTM. Standard practice for classification of soils for engineering purposes. D2487-11, West Conshohocken, PA; 2011.

Berndt, R. D., and Coughlan, K. J. 1976. The nature of changes in bulk density with water content in a cracking clay. Australian Journal of Soil Research, 15, 27-37.

Burton, G. J., Pineda, J. A., Sheng, D., and Airey, D. 2015. Microstructural changes of an undisturbed, reconstituted and compacted high plasticity clay subjected to wetting and drying. Engineering Geology, 193, 363-373.

Chen, F. H., and Ma, G. S. 1987. Swelling and shrinkage behaviour of expansive clays, Proceedings, 6th International Conference on expansive clays, Vol. 1, 127-129, New Delhi, India.

Chen, F.H., 1988. Foundations on expansive soils. Developments in Geotechnical Engineering, vol. 12. Elsevier Publications, The Netherlands.

Chen, R., Xu, T., Zhao, Y.R., Deng, G., Qiao, J., Da Zhou, S., 2019. Effects of net normal stress on hydro-mechanical behaviour of a kaolinite clay soil under different suction paths. Environ. Earth Sci. 78, 1-15.

Chen, W.F., Liu, X.L., 1990. Limit Analysis in Soil Mechanics. Elsevier Science, Amsterdam.

Cui, Y.J., Yahia-Aissa, M., Delage, P., 2002. A model for the volume change behavior of heavily compacted swelling clays. Eng. Geol. 64 (2), 233-250.

Cui Z, He P, Yang W. 2014. Mechanical properties of a silty clay subjected to freezing-thawing. Cold Regions Science and Technology. 98, 26-34.

Cuisinier, O., and Masrouri, F. 2005. Hydromechanical behavior of a compacted swelling soil over a wide suction range. Engineering Geology, 81, 204-212.

Ding LQ, Han Z, Zou WL, Wang XQ. 2020. Characterizing hydro-mechanical behaviours of compacted subgrade soils considering effects of freeze-thaw cycles. Transportation Geotechnics, 24:100392.

Edwin, J. C., and Anthony, J. G. 1979. Effect of freezing and thawing on the permeability and structure of soils. Engineering Geology, 13, 73-92.

Gatabin, C., Talandier, J., Collin, F., Charlier, R., and Dieudonné, A. C. 2016. Competing effects of volume change and water uptake on the water retention behaviour of a compacted MX-80 bentonite/sand mixture. Applied Clay Science, 121-122, $57-62$.

Glade, T., 2005. Linking debris-flow hazard assessments with geomorphology. Geomorphology 66, 189-213.

Grant, K. 1974. The composition of some Australian laterites and lateritic gravel, 2nd International congress of the International Association of Engineering Geology, Sao Paulo, Brazil (Reprint IV32), IV-32.1 to IV-32.15.

Han, Y., Wang, Q., Wang, N., Wang, J., Zhang, X., Cheng, S., Kong, Y., 2018. Effect of freeze-thaw cycles on shear strength of saline soil. Cold Regions Science and Technology, 154(OCT.), 42-53.

Han, Y. , Wang, Q. , Xia, W. , Liu, J. , Wang, J. , Chen, Y., Shen J. 2019. Experimental study on the hydraulic conductivity of unsaturated dispersive soil with different salinities subjected to freeze-thaw. Journal of Hydrology, 583.

Han Z, Vanapalli SK. 2017. Normalizing variation of stiffness and shear strength of compacted fine-grained soils with moisture content. J Geotech Geoenviron Eng.143(9):1-15.

Han, Z., Vanapalli, S.K., 2017. Normalizing variation of stiffness and shear strength of compacted fine-grained soils with moisture content. J. Geotech. Geoenviron. Eng. 143 (9), 04017058.

Holtz, W.G., Gibbs, H. J., 1956. Engineering properties of expansive clays. Am. Soc. Civil Eng. 121 (1), 641-663.

Jiang, J.C., Baker, R., Yamagami, T., 2003. The effect of strength envelope nonlinearity on slope stability computations. Can. Geotech. J. 40 (2), 308-325.

Jones D E, Holtz W G., 1973 Expansive soils - the hidden disaster. Civil Engineering 43 (8), 49-51.

Kamruzzaman A H, CHEW S H, LEE F H. 2009. Structuration and Destructuration Behavior of Cement-Treated Singapore Marine Clay. J Geotech Geoenviron Eng, 135(4):573-589.

Kong, L. W., Zeng, Z. X., Wei, B., Wang, M. 2018. Engineering geological properties of weathered swelling mudstones and their effects on the landslides occurrence in the Yanji section of the Jilin-Hunchun high-speed railway. Bulletin of Engineeing Geology and the Environment, 77(4): 1491-1503.

Lai Y. M., Zhang SM., Yu WB. 2012. A new structure to control frost boiling and frost heave of embankments in cold regions. Cold Regions Science and Technology 79-80: 53-66.

Lee, W., Bohra, N.C., Altschaeffl, A.G., White, T.D., 1997. Resilient modulus of cohesive soils. J. Geotech. Geoenviron. Eng. $123(2), 131-136$.

Li, D., Cheng, Y., 2012. Lower bound limit analysis using nonlinear failure criteria. Procedia. Earth. Planet. Sci. 5 (8), 170- 
174.

Li G, Wang F, Ma W, Fortier R, Mu Y, Mao Y, Hou X, 2018. Variations in strength and deformation of compacted loess exposed to wetting-drying and freeze-thaw cycles. Cold Regions Science and Technology, 151(JUL.):159-167.

Li, S., Qin, S., Bo, Z., Shi, B., 1992. Studies on the Engineering Geology of Expansive Soils in China. Jiangsu Science and Technology Publishing House, Nanjing, China, p. 1.

Lin, B., and Cerato, A. B. 2013. Hysteretic soil water characteristics and cyclic swell-shrink paths of compacted expansive clays. Bulletin of Engineering Geology and the Environment, 72, 61-70.

Liu, G., Toll, D. G., Kong, L. W., and Asquith, J. D. 2020. Matric suction and volume characteristics of compacted clay soil under drying and wetting cycles. Geotechnical Testing Journal, 43 (2).

Liu, J. K., Chang, D., and Yu, Q. M. 2016. Influence of freeze-thaw cycles on mechanical properties of a silty sand. Engineering Geology, 210, 23-32.

Liu, T.J., Xu, X.T., Yang, J., 2017. Experimental study on the effect of freezing-thawing cycles on wind erosion of black soil in Northeast China. Cold Reg. Sci. Technol. 136, 1-8.

Liu, Y. , Huang, R., Liu, E., Hou, F., 2018. Mechanical behaviour and constitutive model of tailing soils subjected to freeze-thaw cycles. European Journal of Environmental and Civil Engineering, 1-23.

Lu, J., Zhang, M., Zhang, X., Pei, W., Bi, J., 2018. Experimental study on the freezing-thawing deformation of a silty clay. Cold Reg. Sci. Technol. 151, 19-27.

Lu, N., Kaya, M., 2013. Power law for elastic moduli of unsaturated soil. J. Geotech. Geoenviron. Eng. 140 (1), $46-56$.

Lu, Y., Liu, S. H., Alonso, E., Wang, L. J., Xu, L., and Li, Z. 2019. Volume changes and mechanical degradation of a compacted expensive soil under freeze-thaw cycles. Cold Regions Science and Technology, 157, 206-214.

Massat L, Cuisinier O, Bihannic I, Claret F, Pelletier M, Masrouri F, Gaboreau S (2016) Swelling pressure development and inter-aggregate porosity evolution upon hydration of a compacted swelling clay. Appl Clay Sci 124-125, 197-210.

Miao, L., Liu, S., Lai, Y., 2002. Research of soil-water characteristics and shear strength features of Nanyang expansive soil. Engineering Geology 65 (4), 261-267.

Nelson, J.D., Miller, D.J., 1992. Expansive Soils Problem Sand Practice in Foundation and Pavement Engineering. Wiley, New York . (259 pp.).

Nowamooz, H., and Masrouri, F. 2008. Hydromechanical behaviour of an expansive bentonite-silt mixture in cyclic suction-controlled drying and wetting tests. Engineering Geology, 101: 154-164.

Pires, L.F., Cooper, M., Cássaro, F.A.M., Reichardt, K., Bacchi, O.O.S., and Dias, N.M.P. 2008. Micromorphological analysis to characterize structure modifications of soil samples submitted to wetting and drying cycles. Catena, 72 : 297-304.

Qi, J., Ma, W., Song, C., 2008. Influence of freeze-thaw on engineering properties of a silty soil. Cold Reg. Sci. Technol. 53 (3), 397-404.

Ramana, K.V., 1993. Humid tropical expansive soils of Trinidad: their geotechnical properties and areal distribution. Engineering Geology 34, 27-44.

Schick, A.P., Grodek, T., Wolman, M.G., 1999. Hydrologic processes and geomorphic constraints on urbanization of alluvial fan slopes. Geomorphology 31, 325-335.

Tang, L., Cong, S., Geng, L., Ling, X., Gan, F., 2018. The effect of freeze-thaw cycling on the mechanical properties of expansive soils. Cold Reg. Sci. Technol. 145, 197-207.

Tripathy S, Subba Rao KS, Fredlund DG. 2002 Water content-void ratio swell-shrink paths of compacted expansive clays. Can Geotech J 39(4): 938-959.

Viklander P. Permeability and volume changes in till due to cyclic freeze-thaw. Can Geotech J 1998;35(3):471-477.

Wang, D., Ma, W., Niu, Y., Chang, X., Wen, Z., 2007. Effects of cyclic freezing and thawing on mechanical properties of Qinghai-Tibet clay. Cold Reg. Sci. Technol. 48 (1), 34-43.

Wang T L, Liu Y J, Yan H, Xu L. An experimental study on the mechanical properties of silty soils under repeated freezethaw cycles. Cold Reg Sci Technol 2015;112:51-65.

Wang, Q., Cui, Y. J., Tang, A. M., Li, X. L. \& Ye, W. M. 2014. Time-and density-dependent microstructure features of compacted bentonite. Soils Found. 54, No. 4, 657-666.

Wang, M., Xu, X., Li, J., Shen, F., Li, Y., 2017. An experiment study on stress relaxation of unsaturated lime-treated expansive clay. Environ. Earth Sci. 76, 1-12.

Xu LL, Liu LJ, Xu SW, Zhang B. 2016. Integrated protection technology for expansive soil slopes in seasonally frozen zones. Chinese Journal of Geotechnical Engineering, 38(S1): 216-220. (In Chinese)

Yarbasi, N., Kalkan, E., Akbulut, S., 2007. Modification of the geotechnical properties, as influenced by freeze-thaw, of granular soil with waste additives. Cold Reg. Sci. Technol. 48 (1), 44-54.

Zeng Z, Kong L, Wang M, Sayem H M. 2018. Assessment of engineering behaviour of an intensely weathered swelling mudstone under full range of seasonal variation and the relationships among measured parameters. Can Geotech J, 55(12):1837-1849.

Zhang, B. Y., Zhang, J. H., and Sun, G. L. 2015. Deformation and shear strength of rockfill materials composed of soft siltstones subjected to stress, cyclical drying/wetting, and temperature variations. Engineering Geology, 190: 87-97.

Zhang, F., Jing, R., Feng, D., Lin, B., 2015. Mechanical properties and an empirical model of compacted silty clay subjected to freeze-thaw cycles. In: International Symposium on Systematic Approaches to Environmental Sustainability in Transportation. Fairbanks City, pp. 200-212.

Zhang JY, Wang YM, Su AS, Xu LL, Wang LX. 2018. Study on the stability of embankment slope under condition of rapid drawdown of high water level. Hydro Science and Cold Zone Engineering, 1(09): 12-17. (In Chinese)

Zou, W., Ye, J., Han, Z., Vanapalli, S.K., Tu, H., 2018. Effect of montmorillonite content and sodium chloride solution on the residual swelling pressure of an expansive clay. Environ. Earth Sci. 77, 677.

Zou, W., Han, Z., Ye, J., 2020. Influence of external stress and initial density on the volumetric behavior of an expansive clay 
during wetting. Environ. Earth Sci. 79, 211. 


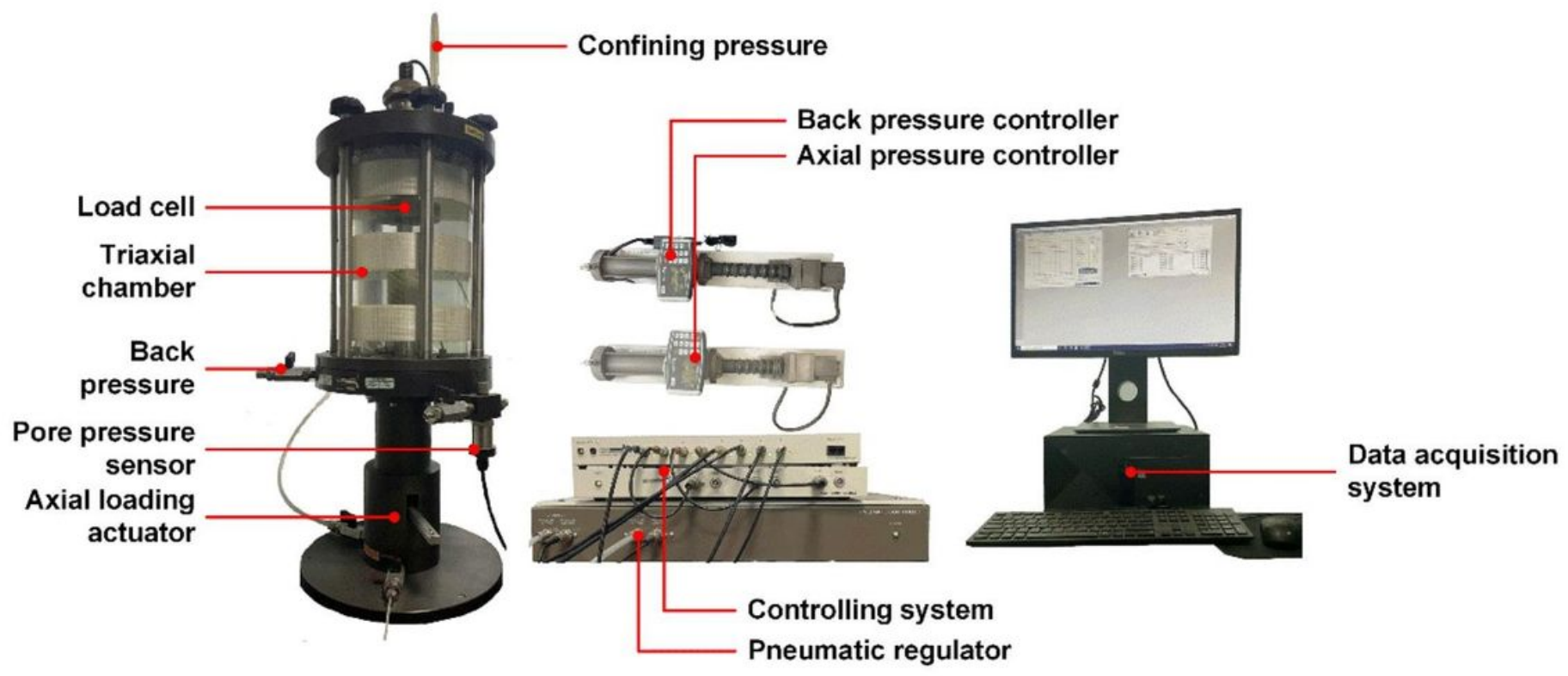

Figure 1

GDS triaxial apparatus for UC and CU tests

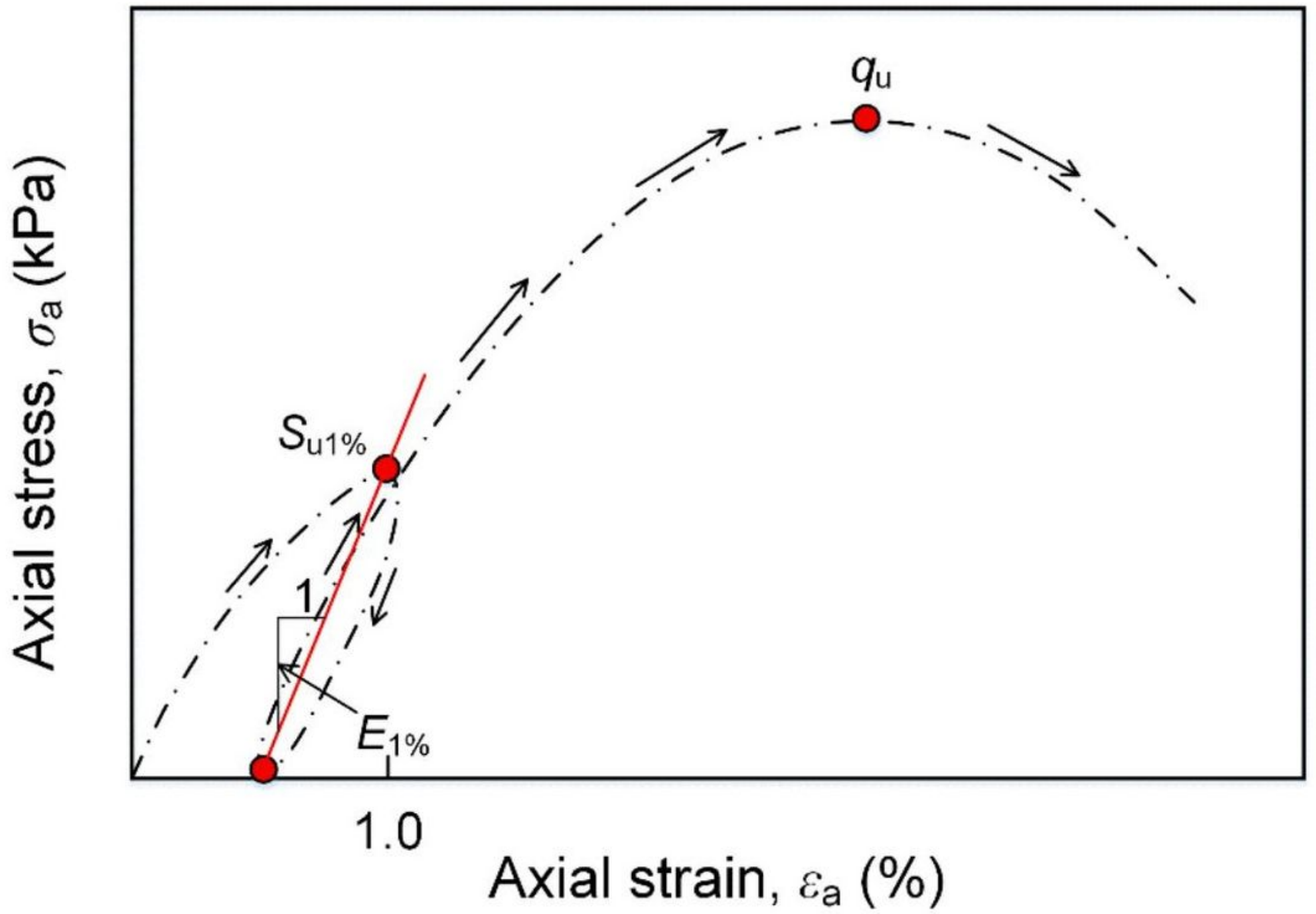


Figure 2

The schematic diagram of the stress-strain relationship and the determination of the $\mathrm{E} 1 \%$, Su1\%, and qu during the revised UC tests

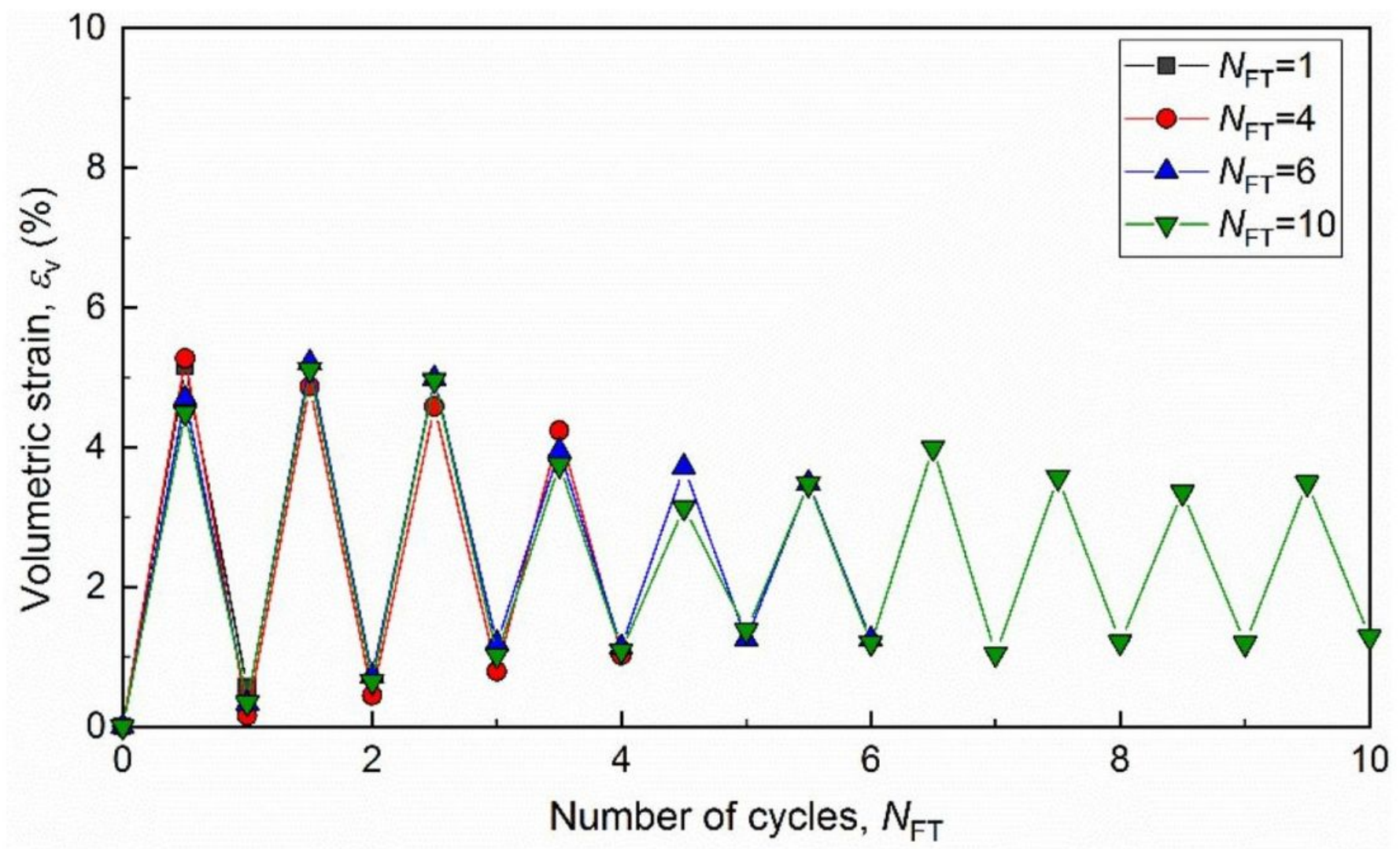

Figure 3

The volumetric variations of specimens during FT cyclic treatments
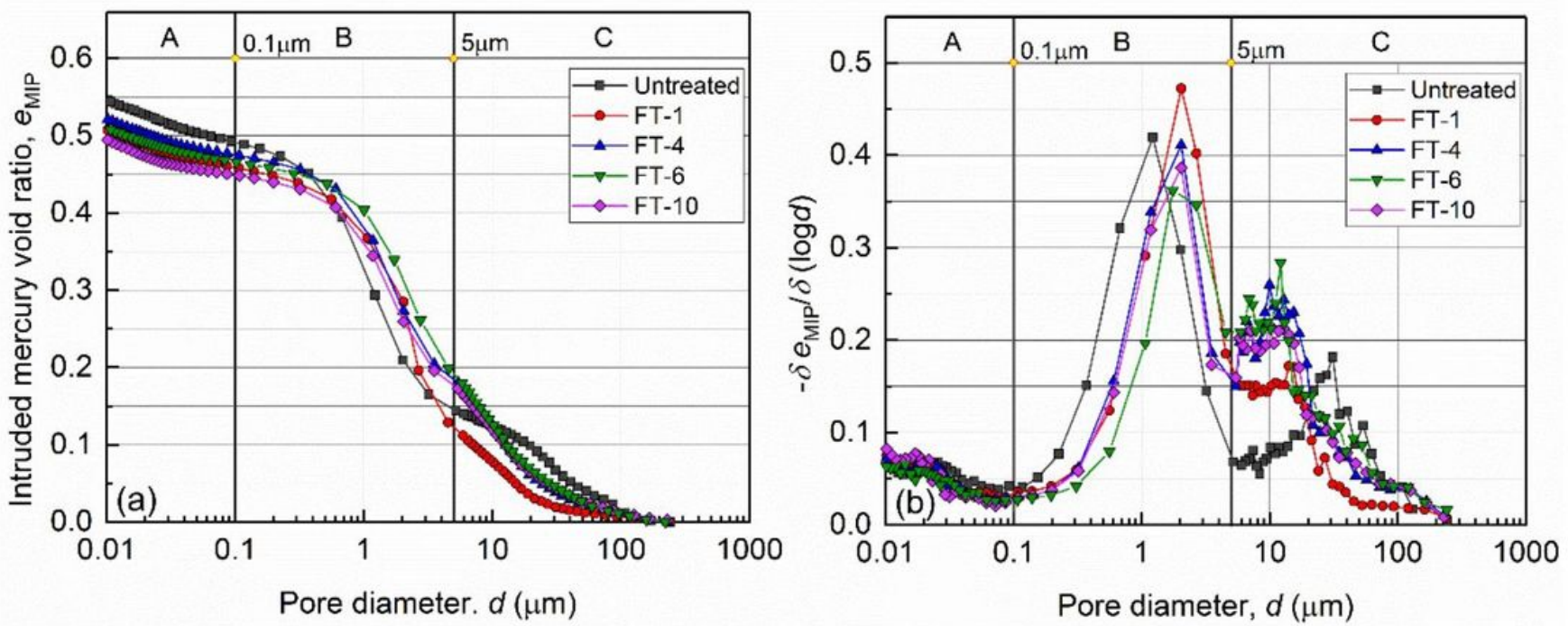
Figure 4

The (a) Cl and (b) PSD curves of specimens after 0, 1, 4, 6 and 10 FT cycles
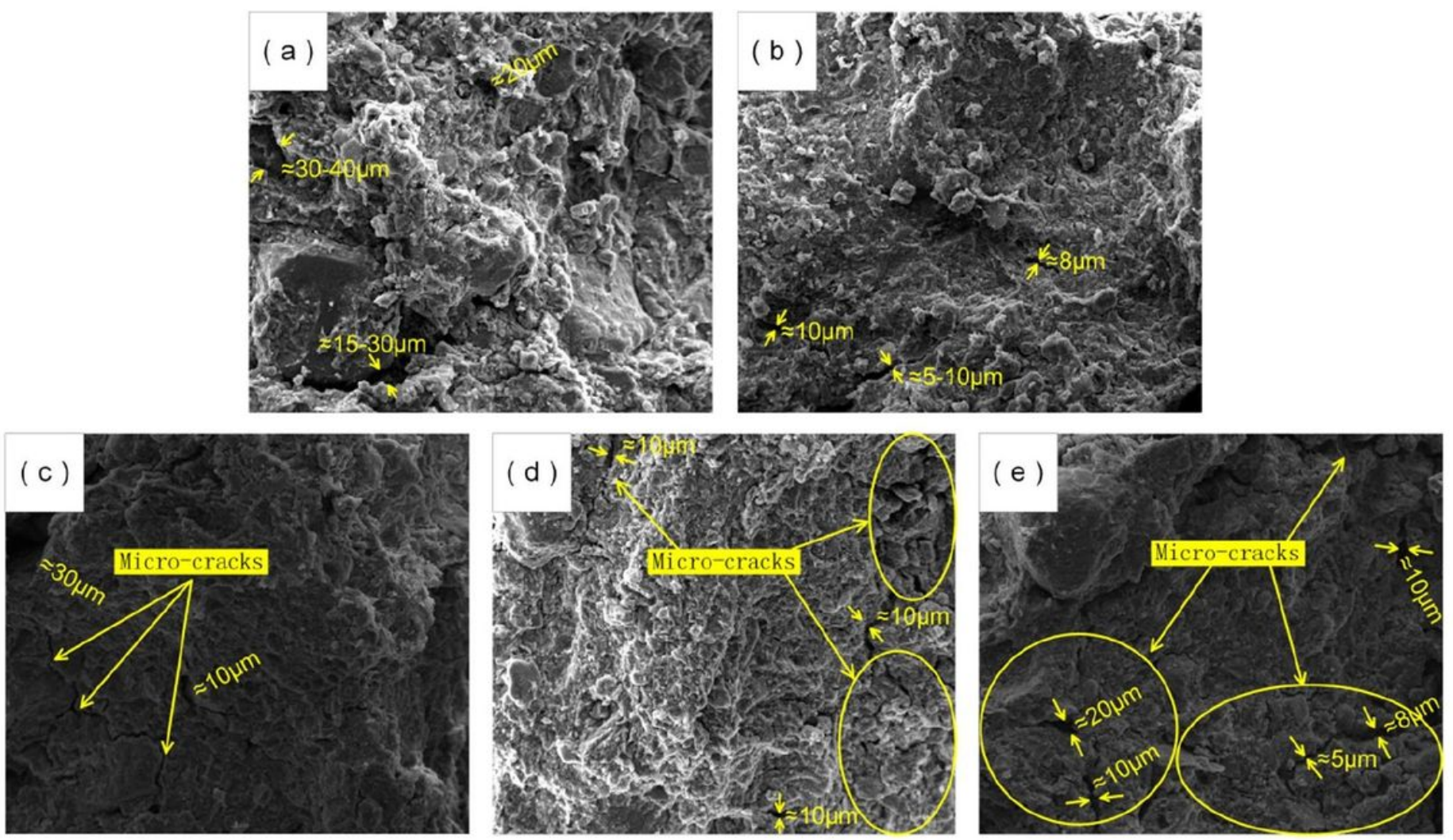

Figure 5

SEM images of (a) untreated specimens and specimens after 1, 4, 6, 10 FT cycles (b-e)
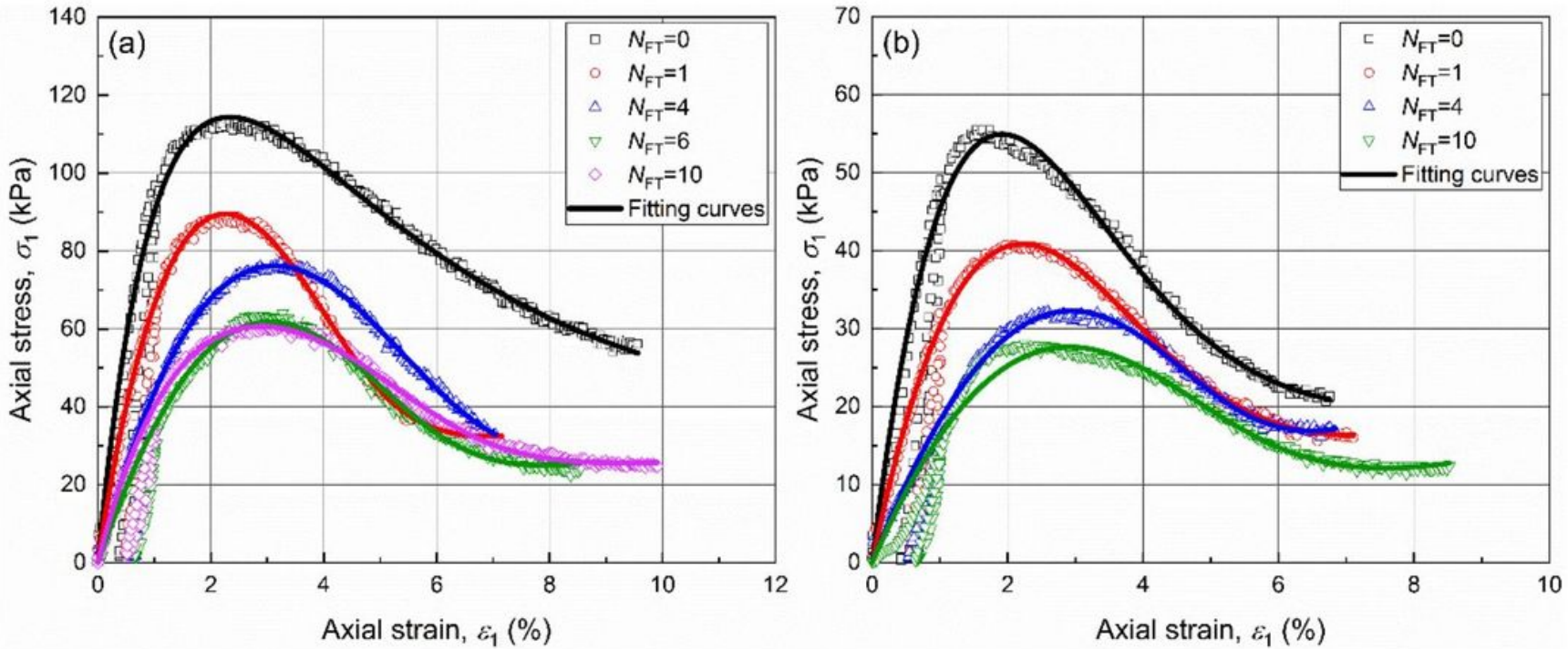

Figure 6 
The UC stress-strain curves of specimens after 0, 1, 4, 6 and 10 FT cycles under (a) unsaturated and (b) saturated conditions
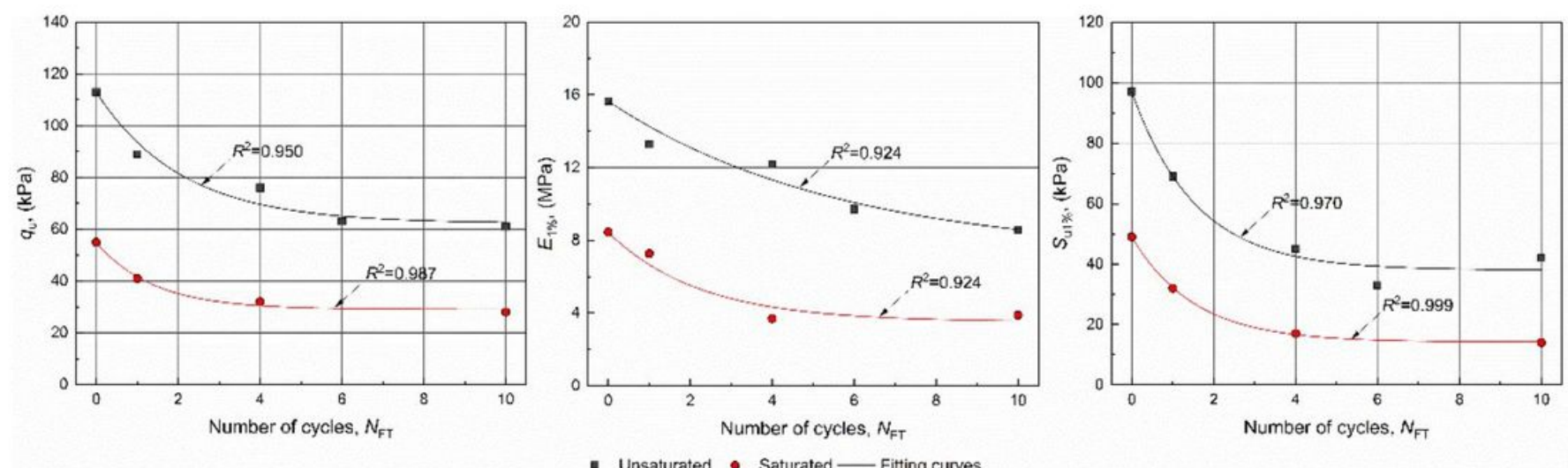

Figure 7

Variation of qu, E1\%, and Su1\% of specimens after 0, 1, 4, 6 and $10 \mathrm{FT}$ cyclic treatments
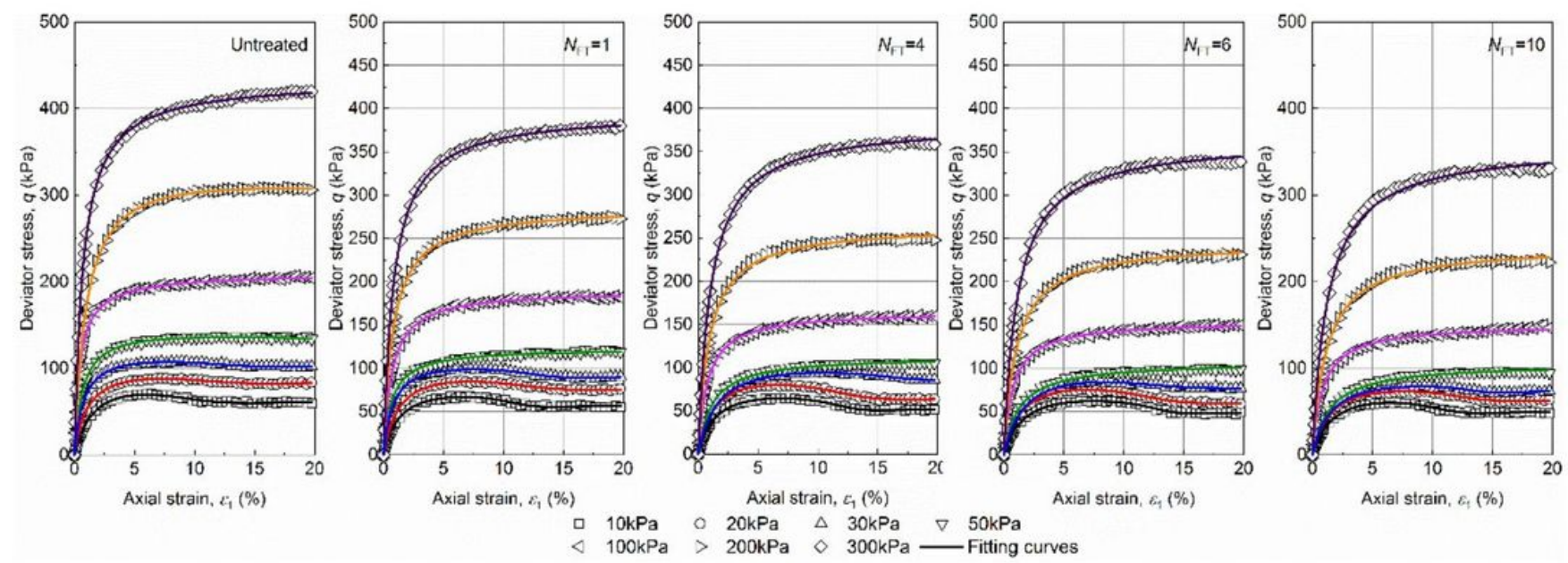

Figure 8

The CU stress-strain relationships of specimens after $0,1,4,6$ and 10 FT cycles under various confining pressures (i.e. 10, 20, 30, 50, 100, 200 and $300 \mathrm{kPa}$ ) 


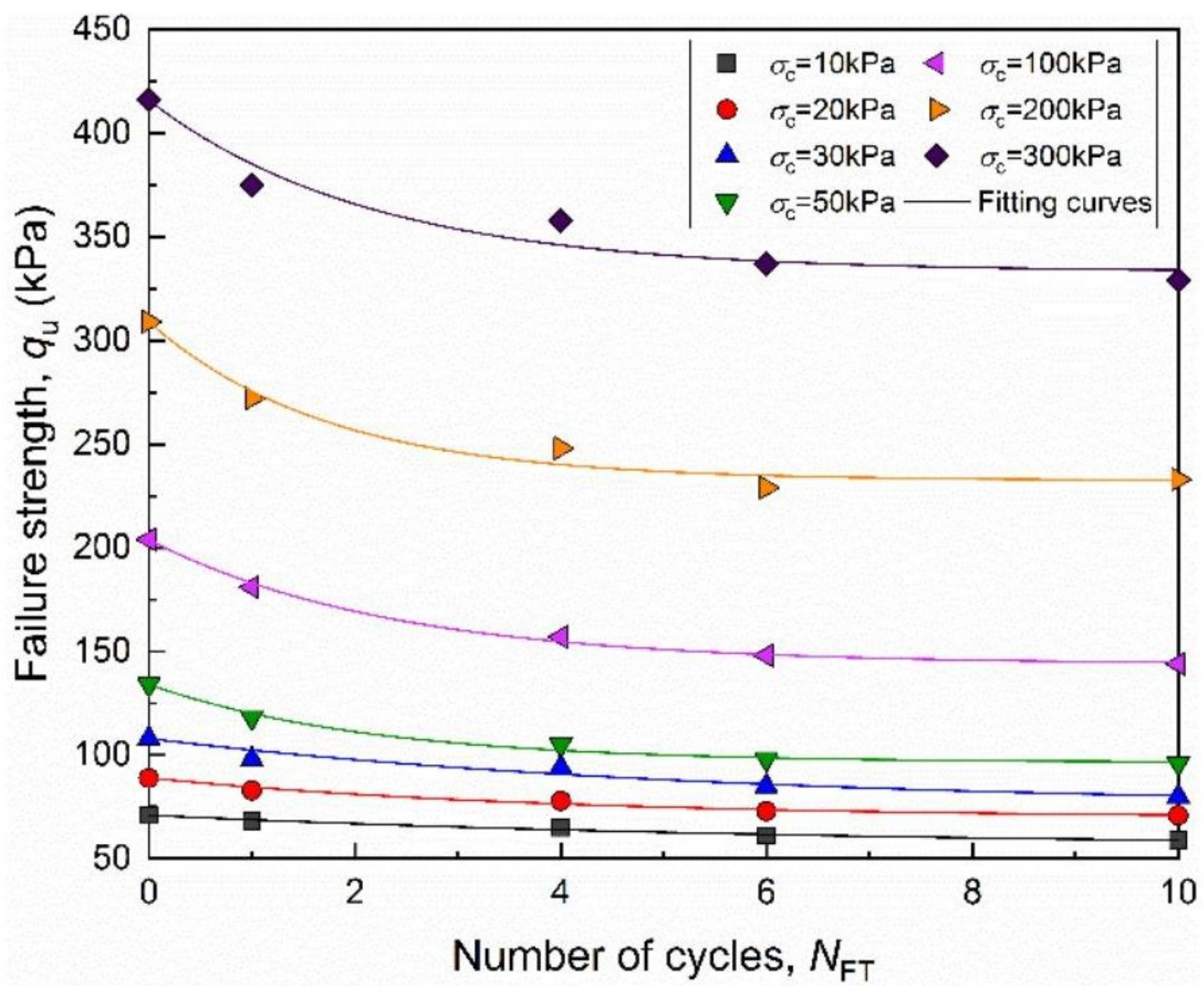

Figure 9

Evolution of Failure strengths obtained from CU tests with the increase of FT cycle numbers 


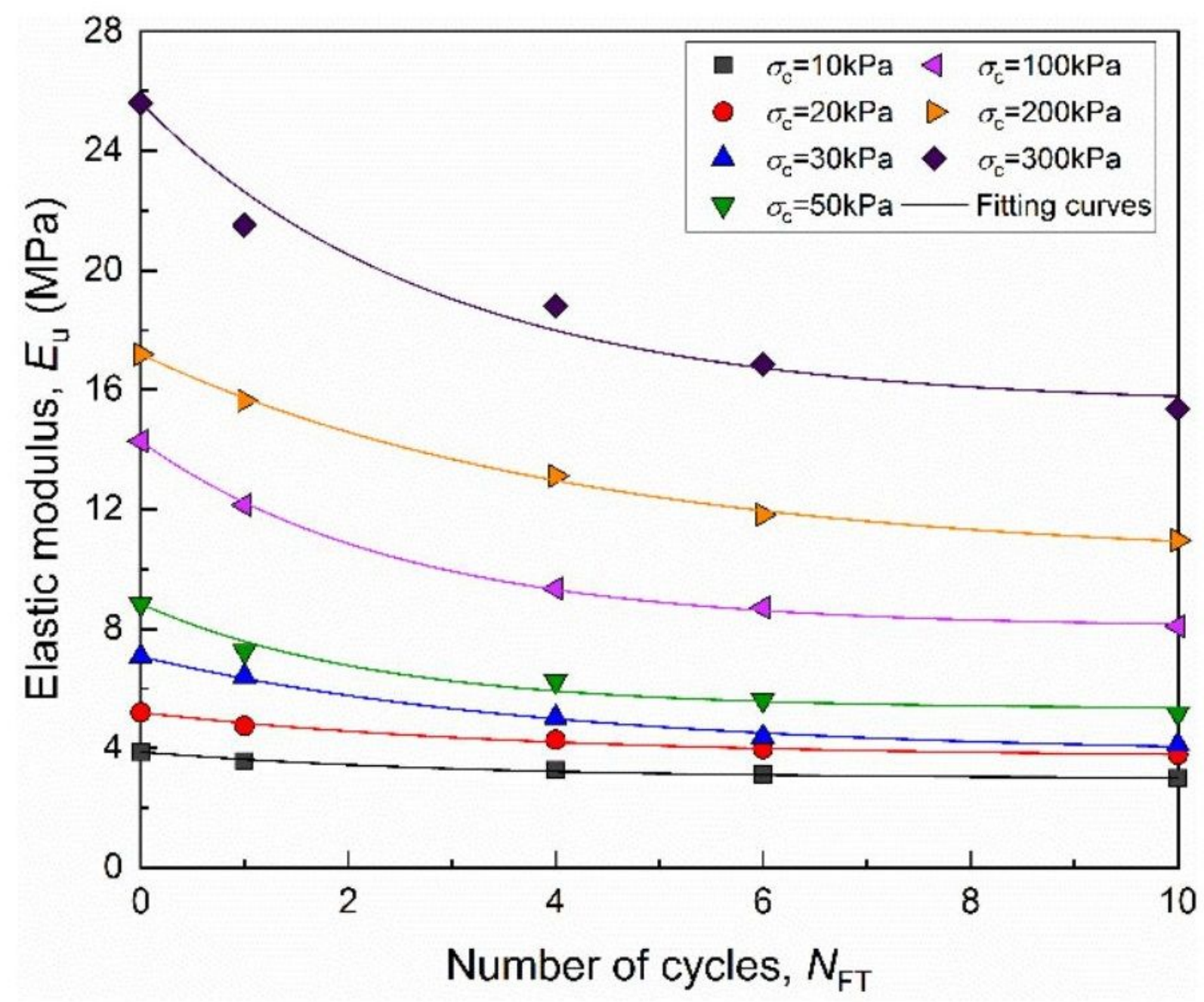

Figure 10

Evolution of Elastic modulus of specimens obtained from CU tests with the increase of FT cycle numbers 

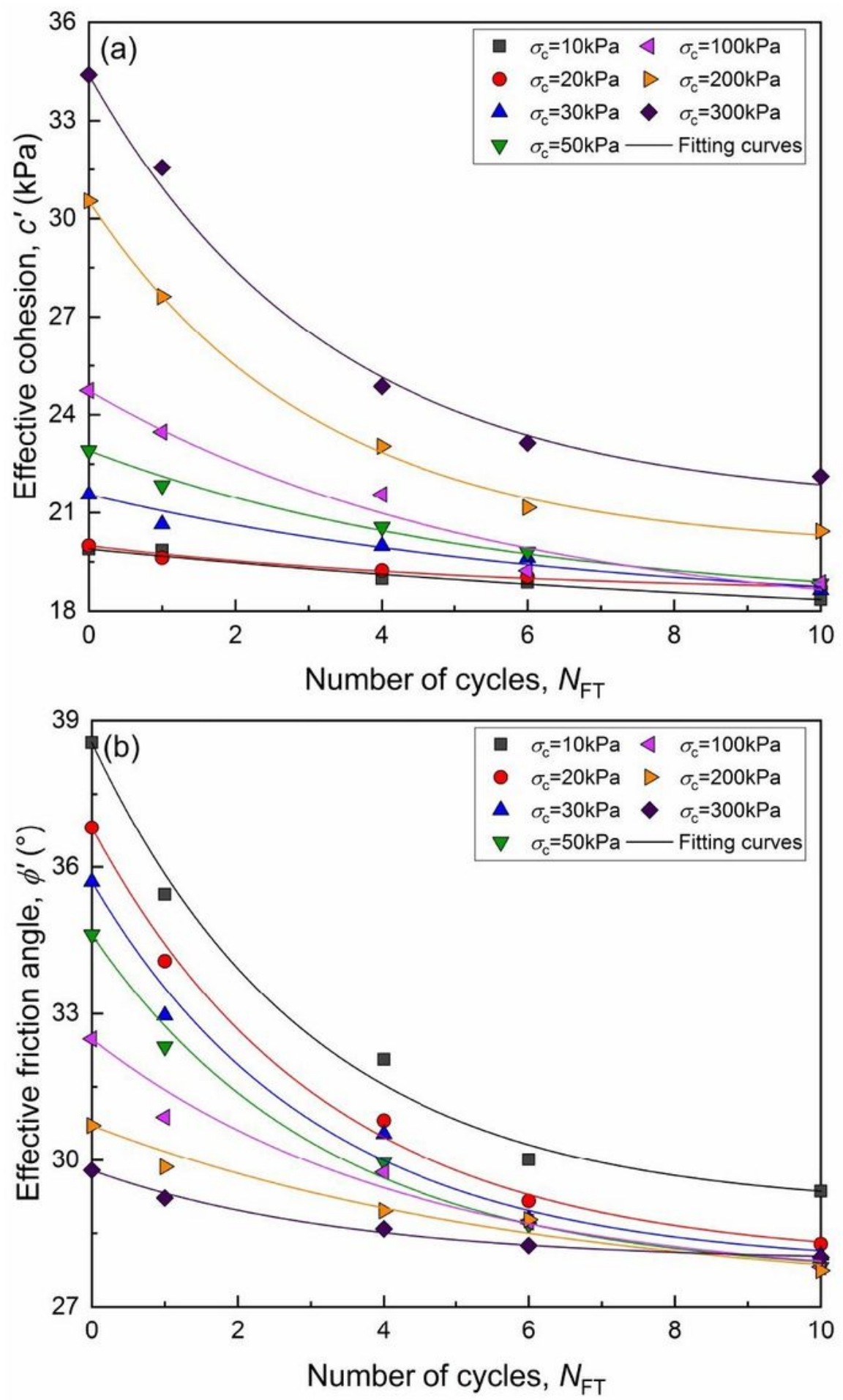

\section{Figure 11}

Evolution of effective cohesions and effective friction angles obtained from CU tests with the increase of FT cycle numbers 

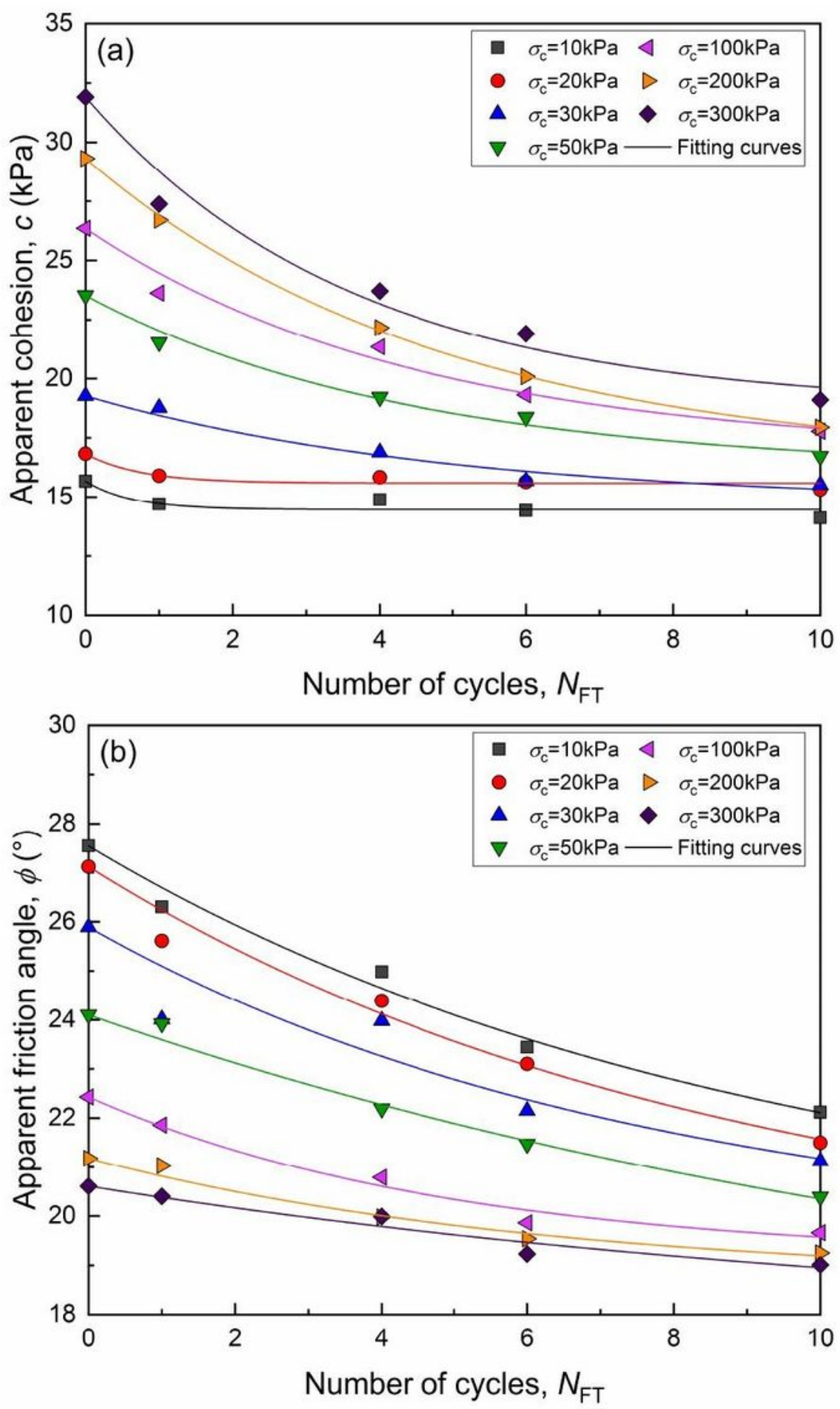

Figure 12

Evolution of apparent cohesions and apparent friction angles obtained from CU tests with the increase of FT cycle numbers 